\title{
Influence of Chronic Radiation Exposure on the Temporal Dynamics of Seeds Germination in Scots Pine Populations from the Bryansk Region Affected By the ChernoByl Accident
}

\section{S. Geras'kin¹, A. Oudalova ${ }^{1,2}$, D. Vasiliyev¹, and A. Kuzmenkov ${ }^{1}$}

${ }^{1}$ Russian Institute of Radiology and Agroecology, Obninsk, Russia

${ }^{2}$ Obninsk Institute for Nuclear Power Engineering of the National Research Nuclear University MEPhl, Studgorodok 1, Obninsk, Kaluga region, 249040, Russia

\section{Abstract}

Temporal dynamics of seeds germination in Scots pine populations growing in the Bryansk region of Russia radioactively contaminated as a result of the Chernobyl accident were investigated over a period of 8 years (2008-2015). In contrast to

Corresponding Author:

S. Geras'kin

stgeraskin@gmail.com

Received: 17 January 2018

Accepted: 25 March 2018

Published: 17 April 2018

Publishing services provided by Knowledge

(c) S. Geras'kin et al. This article is distributed under the terms of the Creative Commons

Attribution License, which permits unrestricted use and redistribution provided that the original author and source are credited.

Selection and Peer-review under the responsibility of the PhysBioSymp17 Conference Committee
G OPEN ACCESS cytogenetic effects in Scots pine, we failed to detect any significant impact of chronic radiation exposure on time dynamics of seeds germination.

Keywords: Scots pine, Chernobyl accident, chronic exposure, temporal dynamics, seeds germination

\section{Introduction}

Long-term monitoring on Scots pine populations inhabiting contaminated as a result of the Chernobyl accident sites in the Bryansk region has shown [1] that the frequency of cytogenetic alterations in the root meristem of germinated seeds from the radioactively contaminated sites significantly exceeded the reference level during the entire observation period (2003-2015). Moreover, it was shown that the frequencies of cytogenetic abnormalities in the reference populations have changed with time in a cyclic fashion [2]. In chronically exposed populations the disturbance was found in the cyclic patterns in temporal dynamics of cytogenetic abnormalities. In addition, a tendency to decrease of frequencies of cytogenetic abnormalities in time as well as an increase in their variability with dose rate were revealed. However, the influence of an increased rate of mutagenesis on the reproductive potential of different species reproducing for many years in areas with elevated levels of radioactive contamination is not clear yet. The analysis of the data on seeds germination in the same populations over a period of 8 years (2008-2015) have shown no consistent differences in reproductive capacity 
between the impacted and reference populations [3]. Presented in [3] the unique data of long-term observations make possible an analysis of the temporal dynamics of germination in Scots pine populations experiencing chronic radiation exposure, which was the goal of this work.

\section{Materials and methods}

Investigations were carried out in the most contaminated districts of the Bryansk region of Russia (Novozybkovskiy, Klintsovskiy, and Krasnogorskiy). Four radioactively contaminated sites: VIUA ( $\left.52^{\circ} 29^{\prime} \mathrm{N}, 31^{\circ} 50^{\prime} \mathrm{E}\right), \mathrm{SB}\left(52^{\circ} 33^{\prime} \mathrm{N}, 31^{\circ} 44^{\prime} \mathrm{E}\right), \mathrm{Z} 1$ ( $53^{\circ} 50^{\prime} \mathrm{N}, 31^{\circ}$ $42^{\prime} \mathrm{E}$ ), and $\mathrm{Zz}\left(53^{\circ} 50^{\prime} \mathrm{N}, 31^{\circ} 42^{\prime} \mathrm{E}\right.$ ) exhibited varying degrees of contamination were chosen approximately $200 \mathrm{~km}$ northeast of the Chernobyl nuclear power plant. The ambient dose rates were measured at the study sites using a hand-held dosimeter (DRG-01T, "Leninez", Russia) at a height of $1 \mathrm{~m}$ above the ground, 5-7 times under each tree where cones were than collected. The dose rates measured at the contaminated sites ranged from 0.3 to $1.3 \mu \mathrm{Gy} / \mathrm{h}$. The reference sites Ref $\left(53^{\circ} 10^{\prime} \mathrm{N}, 33^{\circ} 55^{\prime} \mathrm{E}\right)$ and Ref1 $\left(52^{\circ} 46^{\prime} \mathrm{N}, 32^{\circ} 39^{\prime} \mathrm{E}\right)$ were located in the Vigonichskiy and Unechskiy districts of the Bryansk region. They were selected based on their proximity to the impacted area and their similarity of environmental properties except radioactive contamination (the dose rates at these plots do not exceed $0.1 \mu \mathrm{Gy} / \mathrm{h}$ ). All other readily measurable aspects of the microenvironments at these study sites, except the radiation level, were identical.

Pine cones were collected every year from 2008 to 2015 in November-December from 30-50 years old Scots pine trees. At each site 20-50 cones were taken from each of 20-29 trees at a height of 1.5-2 $\mathrm{m}$ above soil surface. The cones were kept outside for maturing to the end of February, then were moved into a laboratory and were stored at room temperature under reduced humidity until they became fully open and up to seed removal. Seeds were de-winged manually.

To estimate the reproductive potential of pine tree populations the germination (percentage of normally developed seedlings on the $20^{\text {th }}$ day) was evaluated. Seeds were germinated on damp filter paper in Petri dishes at the controlled temperature of $24{ }^{\circ} \mathrm{C}$. Seedlings were considered as normally developed if radicle length exceeded 2 $\mathrm{mm}$. The experiment was performed in four replicates of 50 seeds for each site. Each replica was a combined sample of seeds from different trees of the same site.

The time dynamics of cytogenetic effects was evaluated using eleven regression models (Table 1). The approximation quality of the models was compared using the 
residual sum of squares (SSR), Fisher statistics $(F)$, and the multiple correlation coefficient $\left(R^{2}\right)$. A choice of the model with an optimum ratio of the complexity and goodness of data fitting was carried out using the criteria of structural identification $T=\frac{S S R \cdot n p}{N-n p}[4]$, where $n p$ is the number of parameters in a model, $N$ is the sample volume, as well as the information Akaike test [5]. To test the hypothesis whether mathematical model 2 fits the experimental data significantly better than model 1, the Hayek criteria [6] was applied: $H=\sqrt{\frac{\mu\left(R_{2}^{2}-R_{1}^{2}\right)}{1-R_{2}^{2}}}, R_{2}{ }^{2}>R_{1}{ }^{2}$, where $R_{1}{ }^{2}$ and $R_{2}{ }^{2}$ are multiple correlation coefficients for models 1 and 2 , and $\mu$ is degree of freedom in model 2. $H$-statistics follows the Student distribution.

TABLE 1: Mathematical models used to approximate the time dynamics of the biological effects in Scots pine populations.

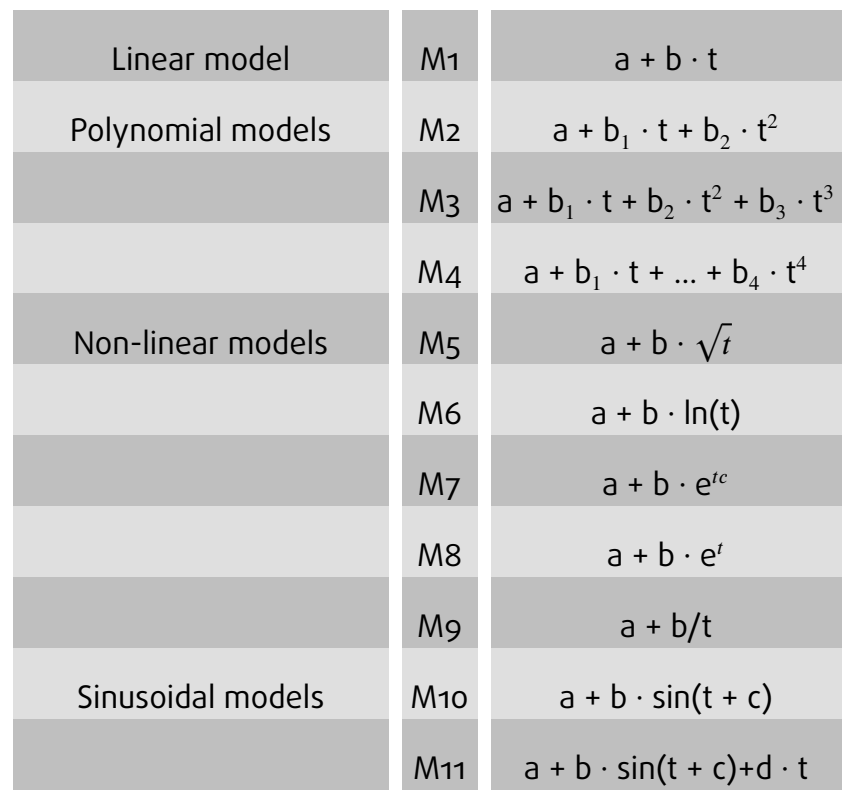

\section{Results and Discussion}

The data combined over 8 years has shown [3] no correlation of germination rate with the level of radiation exposure. Seeds from investigated populations are characterized by high interannual variability of viability. Thereby, the current dose rates at our experimental sites are insufficient to cause discernible changes in seed viability.

The analysis of temporal dynamics has shown that germination of seeds from both reference and affected populations tends to decrease (Figure 1). It was found that temporal dynamics of germination could be best fitted with polynomial models in overwhelming majority of cases (Table 2). 


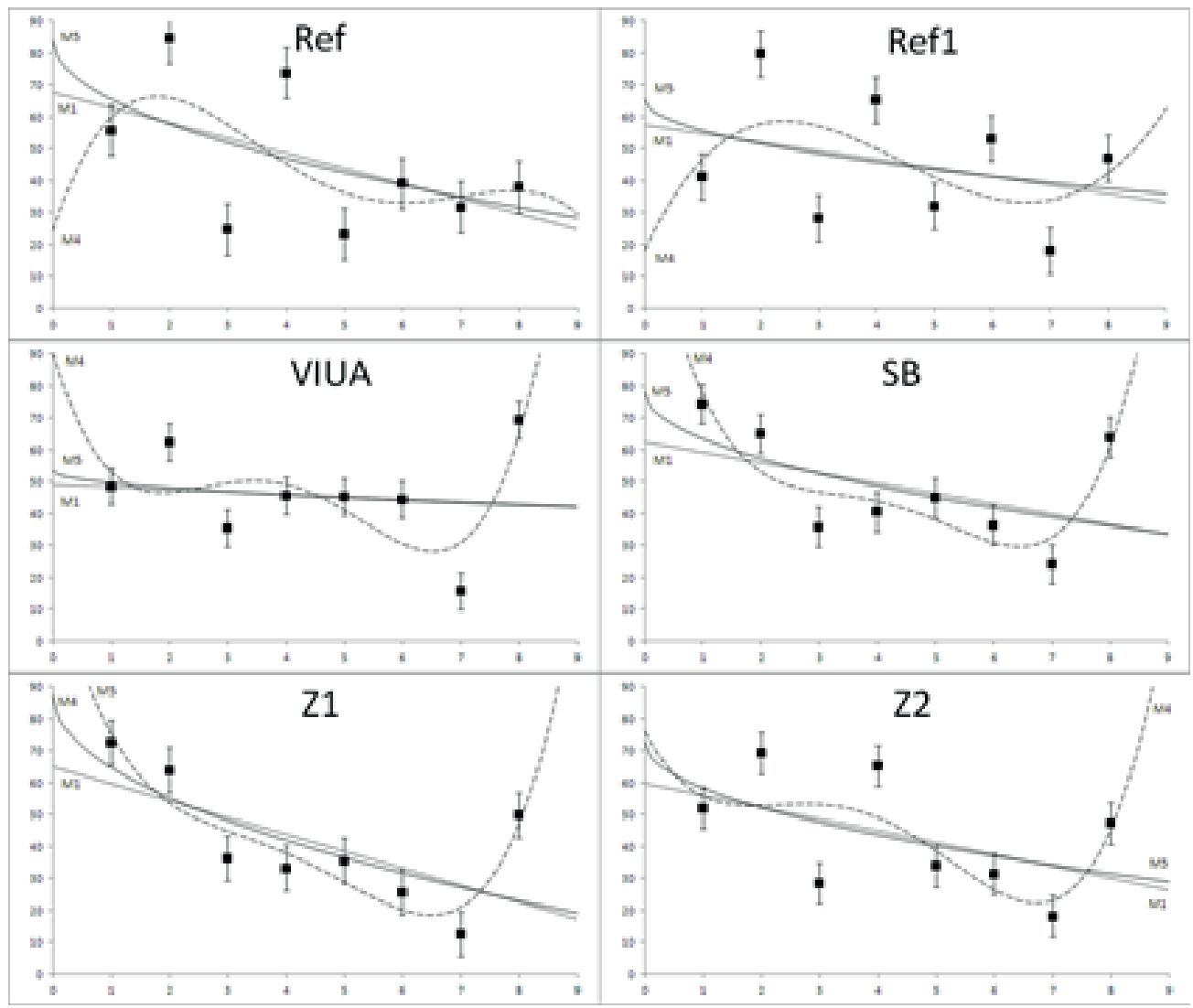

Figure 1: Proportion of germinated seeds from the reference (Ref, Ref1) and affected (VIUA, SB, Z1, Z2) Scots pine populations depending on observation year. Approximations with linear $\left(M_{1}\right)$, polynomial $\left(M_{4}\right)$ and nonlinear (M5) models are shown.

TABLE 2: Comparison of the approximation quality provided by different models for the time dependence of the proportion of germinated seeds.

\begin{tabular}{|c|c|c|c|c|c|c|c|c|}
\hline \multirow[t]{2}{*}{ Model } & \multirow[t]{2}{*}{$n p$} & \multicolumn{3}{|c|}{1 step } & \multicolumn{2}{|c|}{2 step } & \multicolumn{2}{|c|}{3 step } \\
\hline & & $S S R$ & $F$ & $R^{2}, \%$ & $T$ & $A I C$ & $H$ & $\alpha_{H}$ \\
\hline \multicolumn{9}{|c|}{ Ref } \\
\hline$M_{1}$ & 2 & 2721,48 & 2,09 & 25,8 & 907,16 & 75,34 & - & - \\
\hline$M 2$ & 3 & 2665,38 & 0,94 & 27,3 & 1599,23 & 77,17 & 0,32 & 0,62 \\
\hline$M_{3}$ & 4 & 2525,11 & 0,60 & 31,1 & 2525,11 & 78,74 & 0,55 & 0,70 \\
\hline$M_{4}$ & 5 & 2475,90 & 0,36 & 32,5 & 4126,49 & 80,58 & 0,55 & 0,70 \\
\hline M5 & 2 & 2710,35 & 2,12 & 26,1 & 903,45 & 75,31 & 0,16 & 0,56 \\
\hline M6 & 2 & 2769,29 & 1,95 & 24,5 & 923,10 & 75,48 & & \\
\hline M7 & 3 & 2721,48 & 0,87 & 25,8 & 1632,89 & - & & \\
\hline M8 & 2 & 3381,77 & 0,50 & 7,7 & 1127,26 & 77,07 & & \\
\hline M9 & 2 & 3049,44 & 1,21 & 16,8 & 1016,48 & 76,25 & & \\
\hline M10 & 3 & 3217,57 & 0,35 & 12,2 & 1930,54 & 78,68 & & \\
\hline M11 & 4 & 2553,18 & 0,58 & 30,4 & 2553,18 & 78,82 & 0,51 & 0,69 \\
\hline \multicolumn{9}{|c|}{ Ref1 } \\
\hline M1 & 2 & 2589,29 & 0,71 & 10,6 & 863,10 & 74,94 & - & - \\
\hline
\end{tabular}




\begin{tabular}{|c|c|c|c|c|c|c|c|c|}
\hline \multirow[t]{2}{*}{ Model } & \multirow[t]{2}{*}{$n p$} & \multicolumn{3}{|c|}{1 step } & \multicolumn{2}{|c|}{2 step } & \multicolumn{2}{|c|}{3 step } \\
\hline & & SSR & $F$ & $R^{2}, \%$ & $T$ & $A I C$ & $H$ & $\alpha_{H}$ \\
\hline$M_{2}$ & 3 & 2587,89 & 0,30 & 10,6 & 1552,73 & 76,94 & & \\
\hline$M_{3}$ & 4 & 2301,45 & 0,34 & 20,5 & 2301,45 & 78,00 & 0,71 & 0,75 \\
\hline$M_{4}$ & 5 & 2300,47 & 0,19 & 20,5 & 3834,12 & 79,99 & 0,61 & 0,72 \\
\hline M5 & 2 & 2623,02 & 0,62 & 9,4 & 874,34 & 75,04 & & \\
\hline M6 & 2 & 2684,08 & 0,47 & 7,3 & 894,69 & 75,23 & & \\
\hline M7 & 3 & 2588,61 & 0,30 & 10,6 & 1553,17 & - & & \\
\hline M8 & 2 & 2818,19 & 0,16 & 2,6 & 939,40 & 75,62 & & \\
\hline M9 & 2 & 2822,18 & 0,15 & 2,5 & 940,73 & 75,63 & & \\
\hline M10 & 3 & 2628,26 & 0,25 & 9,2 & 1576,96 & 77,06 & & \\
\hline M11 & 4 & 2465,48 & 0,23 & 14,8 & 2465,48 & 78,55 & 0,44 & 0,66 \\
\hline \multicolumn{9}{|c|}{ VIUA } \\
\hline$M_{1}$ & 2 & 1834,36 & 0,07 & 1,2 & 611,45 & 72,18 & - & - \\
\hline$M 2$ & 3 & 1570,90 & 0,46 & 15,4 & 942,54 & 72,94 & 0,92 & 0,80 \\
\hline$M_{3}$ & 4 & 1188,42 & 0,75 & 36,0 & 1188,42 & 72,71 & 1,47 & 0,90 \\
\hline$M_{4}$ & 5 & 942,63 & 0,73 & 49,2 & 1571,05 & 72,86 & 1,68 & 0,93 \\
\hline M5 & 2 & 1817,48 & 0,13 & 2,1 & 605,83 & 72,11 & 0,23 & 0,59 \\
\hline M6 & 2 & 1803,51 & 0,18 & 2,9 & 601,17 & 72,05 & 0,32 & 0,62 \\
\hline M7 & 3 & 1223,71 & 1,29 & 34,1 & 734,22 & - & 1,58 & 0,92 \\
\hline M8 & 2 & 1681,31 & 0,63 & 9,5 & 560,44 & 71,48 & 0,74 & 0,76 \\
\hline M9 & 2 & 1811,31 & 0,19 & 3,0 & 603,77 & 72,04 & 0,33 & 0,63 \\
\hline M10 & 3 & 1596,14 & 0,41 & 14,1 & 957,68 & 73,07 & 0,87 & 0,79 \\
\hline M11 & 4 & 1596,16 & 0,22 & 14,1 & 1596,16 & 75,07 & 0,78 & 0,77 \\
\hline \multicolumn{9}{|c|}{ SB } \\
\hline$M_{1}$ & 2 & 1717,16 & 1,53 & 20,3 & 572,39 & 71,65 & - & - \\
\hline$M_{2}$ & 3 & 702,01 & 4,58 & 64,7 & 421,20 & 66,50 & 2,51 & 0,98 \\
\hline$M_{3}$ & 4 & 651,75 & 3,08 & 69,8 & 651,75 & 67,90 & 2,56 & 0,98 \\
\hline M4 & 5 & 439,45 & 2,93 & 79,6 & 732,41 & 66,75 & 2,95 & 0,987 \\
\hline M5 & 2 & 1539,64 & 2,40 & 28,6 & 513,21 & 70,78 & 0,84 & 0,78 \\
\hline M6 & 2 & 1361,01 & 3,49 & 36,8 & 453,67 & 69,80 & 1,25 & 0,87 \\
\hline M7 & 3 & 1717,11 & 0,64 & 20,3 & 1030,27 & - & & \\
\hline M8 & 2 & 2124,64 & 0,09 & 1,4 & 708,21 & 73,36 & & \\
\hline M9 & 2 & 1155,44 & 5,19 & 46,4 & 385,15 & 68,49 & 1,71 & 0,93 \\
\hline M10 & 3 & 1588,54 & 0,89 & 26,3 & 953,12 & 73,03 & 0,64 & 0,73 \\
\hline M11 & 4 & 1238,93 & 0,99 & 42,5 & 1238,93 & 73,04 & 1,24 & 0,87 \\
\hline \multicolumn{9}{|c|}{$\mathrm{Z}_{1}$} \\
\hline$M_{1}$ & 2 & 1570,39 & 4,53 & 43,0 & 523,46 & 70,94 & - & - \\
\hline$M_{2}$ & 3 & 603,78 & 8,92 & 78,1 & 362,27 & 65,29 & 2,83 & 0,99 \\
\hline$M_{3}$ & 4 & 499,96 & 5,99 & 81,8 & 499,96 & 65,79 & 2,92 & 0,99 \\
\hline
\end{tabular}




\begin{tabular}{|c|c|c|c|c|c|c|c|c|}
\hline \multirow[t]{2}{*}{ Model } & \multirow[t]{2}{*}{$n p$} & \multicolumn{3}{|c|}{1 step } & \multicolumn{2}{|c|}{2 step } & \multicolumn{2}{|c|}{3 step } \\
\hline & & $S S R$ & $F$ & $R^{2}, \%$ & $T$ & $A I C$ & $H$ & $\alpha_{H}$ \\
\hline$M_{4}$ & 5 & 359,50 & 4,98 & 86,9 & 599,16 & 65,15 & 3,17 & 0,99 \\
\hline M5 & 2 & 1315,29 & 6,55 & 52,2 & 438,43 & 69,52 & 1,07 & 0,84 \\
\hline M6 & 2 & 1110,18 & 8,89 & 59,7 & 370,06 & 68,17 & 1,58 & 0,92 \\
\hline M7 & 3 & 1570,39 & 1,89 & 43,0 & 942,24 & - & & \\
\hline M8 & 2 & 2730,91 & 0,05 & 0,8 & 910,30 & 75,37 & & \\
\hline M9 & 2 & 1020,75 & 10,17 & 62,9 & 340,25 & 67,49 & 1,79 & 0,94 \\
\hline M10 & 3 & 1951,04 & 1,03 & 29,2 & 1170,62 & 74,68 & & \\
\hline M11 & 4 & 1033,29 & 2,22 & 62,5 & 1033,29 & 71,59 & 1,44 & 0,90 \\
\hline \multicolumn{9}{|c|}{$\mathrm{Zz}$} \\
\hline$M_{1}$ & 2 & 1755,50 & 1,98 & 24,8 & 585,17 & 71,83 & - & - \\
\hline$M 2$ & 3 & 1687,44 & 0,96 & 27,7 & 1012,46 & 73,51 & 0,45 & 0,67 \\
\hline$M_{3}$ & 4 & 1357,79 & 0,96 & 41,9 & 1357,79 & 73,78 & 1,09 & 0,84 \\
\hline$M_{4}$ & 5 & 1237,64 & 0,67 & 47,0 & 2062,74 & 75,04 & 1,12 & 0,85 \\
\hline M5 & 2 & 1740,67 & 2,05 & 25,5 & 580,22 & 71,76 & 0,24 & 0,59 \\
\hline M6 & 2 & 1770,98 & 1,92 & 24,2 & 590,33 & 71,90 & & \\
\hline M7 & 3 & 1755,50 & 0,82 & 24,8 & 1053,30 & - & & \\
\hline M8 & 2 & 2278,83 & 0,15 & 2,4 & 759,61 & 73,92 & & \\
\hline M9 & 2 & 1934,53 & 1,25 & 17,2 & 644,84 & 72,61 & & \\
\hline M10 & 3 & 1839,94 & 0,67 & 21,2 & 1103,96 & 74,21 & & \\
\hline M11 & 4 & 1527,71 & 0,71 & 34,6 & 1527,71 & 74,72 & 0,77 & 0,77 \\
\hline
\end{tabular}

Note: $n p$ is the number of model parameters; SSR - sum of squared residuals; $F$ - Fisher's statistics; $R^{2}$ - multiple correlation coefficient; $T$ - structural identification test; AIC - information Akaike test; $H$ and $\alpha_{H}$ - the value and significance level of the Hayek's criteria.

The values of the tests demonstrating that the approximation quality of a model exceeds that of the $M_{1}$ linear model are boldfaced; the best value of the criterion is underlined.

Finally, in contrast to cytogenetic effects recognized in the same pine tree populations with confidence, we failed to detect any significant impact of chronic radiation exposure on time dynamic of Scots pine seed germinating capacity within the range of $10-38 \mathrm{mGy} / \mathrm{y}$.

\section{Acknowledgements}

The present study was supported by the Russian Scientific Foundation (grant 14-1400666). 


\section{References}

[1] S.A. Geras'kin, N.S. Dikareva, A.A. Oudalova, D.V. Vasil'ev, and P.Yu. Volkova, "The consequences of chronic radiation exposure of Scots pine in the remote period after the Chernobyl accident", Russian J. Ecology, vol. 47, pp. 26-38, 2016.

[2] S. Geras'kin, A. Kuzmenkov, and D. Vasiliyev, "Time dynamics of cytogenetic effects in chronically irradiated Scots pine populations", Radiation Biology. Radioecology, vol. 58, 2018.

[3] S. Geras'kin, D. Vasiliyev, E. Makarenko, P. Volkova, and A. Kuzmenkov, "Influence of long-term chronic exposure and weather conditions on Scots pine populations", Environmental Science and Pollution Research, vol. 24, pp. 11240-11253, 2017.

[4] S.A. Geras'kin, and B.I. Sarapul'tzev, "Automatic classification of biological objects on the level of their radioresistance", Automation Remote Control vol. 54, pp. 182189, 1993.

[5] K.P. Burnham, and D.R. Anderson. Model Selection and Multimodel Inference: a Practical Information-Theoretic Approach. New York, USA: Springer, 2002.

[6] J. Gofman. Radiation-induced cancer from low dose exposure: an independent analysis. San Francisco, USA: CNR Book Division, 1990. 